\title{
МОДЕЛЬНОЕ ЗАКОНОДАТЕЛЬСТВО СТРАН СНГ В ОБЛАСТИ ПРИВЛЕЧЕНИЯ ИНСТИТУТОВ ГРАЖДАНСКОГО ОБЩЕСТВА К УЧАСТИЮ В ОБЕСПЕЧЕНИИ НАЦИОНАЛЬНОЙ БЕЗОПАСНОСТИ ГОСУДАРСТВА
}

Аннотация. Статья посвящена правовому регулированию института участия граждан 8 обеспечении национальной безопасности в модельном законодательстве стран Содружества Независимых Государств. Автором раскрыты направления развития нормотворчества в данной сфере и изложены проблемы находящегося в стадии своего формирования модельного законодательства, регулирующего участие граждан в патриотическом воспитании, обеспечении пограничной безопасности, противодействии терроризму и экстремизму. На основании изучения современной геополитической обстановки отражена необходимость расширения форм участия граждан в обеспечении национальной безопасности. Проведен анализ модельных законов стран Содружества Независимых Государств, регулирующего участие граждан в обеспечении национальной безопасности государства, и характера современных военных угроз. Охарактеризован правовой институт участия граждан в обеспечении национальной безопасности и правовой статус граждан как субъектов правоотношений по обеспечению начиональной безопасности. Сформулированы рекомендации относительно планируемых к разработке в 2016-2020 г2. Межпарламентской Ассамблеей государств - участников СНГ модельных законов об участии институтов гражданского общества в обеспечении национальной безопасности и о правовом регулировании деятельности частных военных компаний.

Ключевые слова: Модельный закон, начиональная безопасность, угроза, участие, гражданское общество, правовой статус, экстремистская деятельность, частная военная компания, ограничение, гарантия.

Abstract: This article is dedicated to the legal regulation of the institution of civil participation in provision of national security within the model legislation of the CIS countries. The author explains the vectors of development of the legislation in this sphere and states the problems that are currently in the stage of its formation of the model legislation, which regulates civil participation in patriotic upbringing, provision of border security, and counteraction of terrorism and extremism. Based on the study of the modern geopolitical situation, the author demonstrates the necessity to expand the forms of civil participation in ensuring national security. Analysis is conducted on the model laws of the CIS countries that regulate the civil participation in provision of national security, as well as on the nature of modern military threats. The author gives characteristics to the institution of civil participation in provision of national security and the legal status of citizens as the constituents of legal relations on provision of national security. Recommendations are made regarding the 20162020 Interparliamentary Assembly of Member Nations of the Commonwealth of Independent States plans to develop model laws on participation of civil institutions in provision of national security and the legal regulation of the activity of private military contractors.

Keywords: Private military contractor, extremist activities, legal status, civil society, participation, threat, national security, model law, limitation, guarantee. 
овременное состояние внешнеполитических отношений, процесс глобализации, а также взаимосвязь стабильности конституционного строя и военной безопасности государства обуславливают необходимость своевременной выработки средств оперативного реагирования на различного рода проявления, представляющие или способные стать причиной, условием возникновения угрозы национальной безопасности государства. На уровне стран СНГ разрабатываются модельные законы, отражающие актуальность взаимодействия государства и институтов гражданского общества. При разработке таких законов должно учитываться расширение возможностей привлечения граждан к участию в обеспечении национальной безопасности.

Следует отметить повышение интереса юридической науки к проблемам взаимодействия государственных органов с институтами гражданского общества [1-5]. При этом в научной литературе отсутствуют положения, направленные на конкретизацию содержания модельных законов об участии институтов гражданского общества в обеспечении национальной безопасности как принятых, так и находящихся в стадии разработки.

Анализ принятых модельных законов говорит о начальной стадии формирования законодательства в данной сфере. Модельный закон СНГ «О публично-частном партнерстве» [6], отражающий в целом общие положения об участии в управлении делами государства, в частности, в сфере охраны окружающей среды, определяя правовой статус сторон соглашения о публично-частном партнерстве, указывает на необходимость соблюдения установленных ограничений, а также осуществления контроля публичного партнера в отношении частных лиц. В целях совершенствования национального законодательства стран - участников СНГ предлагается определить правовой информационный статус личности, предусмотрев право на информационное участие в государственном управлении [7].

Некоторые из актов направлены на регулирование отдельных форм участия граждан в обеспечении национальной безопасности государства. Так, например, Модельный закон «О добровольчестве (волонтерстве)» [8] предусматривает, что волонтерская (добровольческая) деятельность включает в себя участие в мероприятиях по гражданской обороне, содействие патриотическому, духовно-нравственному воспитанию детей и молодежи, оказание бесплатной юридической помощи, участие в защите и охране окружающей среды и т.д.

Согласно ст. 6 Модельного закона СНГ «О патриотическом воспитании» [9] структуру системы патриотического воспитания составляют организации, осуществляющие патриотическое воспитание, педагогические работники, граждане, государственные и иные органы, осуществляющие управление в сфере патриотического воспитания, и созданные ими консультативные, совещательные и иные органы, организации, общественные объединения. Система патриотического воспитания призвана обеспечить целенаправленное формирование у граждан активной позиции, способствовать всемерному включению их в решение социально значимых задач, создавать условия для формирования у них сознания, ориентированного в соответствии с национальными интересами государства. Система должна готовить молодежь и побуждать представителей других поколений к такой активной деятельности, в которой знания и жизненный опыт соединяются с позицией гражданского и патриотического долга, становясь сопричастными с судьбой Отечества, а личные интересы соединяются с интересами общества. 
Согласно ст. 8 Модельного закона «О противодействии терроризму» [10] информационно-пропагандистское противодействие терроризму осуществляется в целях объединения усилий государственных органов и институтов гражданского общества в профилактике терроризма. Государственные органы обязаны стимулировать участие в этой деятельности представителей средств массовой информации, юридических лиц, институтов гражданского общества, религиозных объединений. В ст. 5 Модельного закона «О противодействии экстремизму» [11] определено, что общественные и религиозные объединения, международные и иные организации, граждане участвуют в противодействии экстремизму через органы государственной власти и органы местного самоуправления. В ст. 6 закона обращено внимание на приоритетное осуществление профилактических, в том числе воспитательных, пропагандистских мер.

Модельный закон «О приграничном сотрудничестве» [12] в числе участников приграничного сотрудничества называет учреждения, предприятия, общественные организации, иные юридические лица, находящиеся на территории приграничного региона, а также физические лица, а в числе форм взаимодействия - договор (контракт) гражданско-правового характера, что в настоящее время не находит широкого применения на практике.

Модельный закон «О пограничной безопасности» [13], одним из принципов которой является упреждающий характер мер по ее обеспечению, определил в ст. 4, что государство обеспечивает правовую и социальную защиту гражданам, общественным и иным организациям и объединениям, оказывающим содействие в обеспечении безопасности в пограничном пространстве. Граждане, общественные и иные организации и объединения являются субъектами системы обеспечения пограничной безопасности, обладают правами и обязанностями по участию в обеспечении безопасности. Согласно ст. 24 закона органы местного самоуправления имеют право ограничивать деятельность организаций, расположенных на соответствующих территориях, и физических лиц в связи с нарушениями требований вплоть до принятия решения о приостановлении деятельности организаций, организовывать общественные обсуждения и опросы среди населения. Уполномоченный государственный орган в области пограничной безопасности осуществляет государственный контроль за соблюдением требований к обеспечению пограничной безопасности, участвует в разработке государственных программ обучения населения в этой сфере.

Статья 28 данного закона устанавливает, что предприятия, учреждения и организации, общественные объединения оказывают помощь государственным органам, непосредственно участвующим в обеспечении пограничной безопасности, исполняют их законные предписания, предоставляют необходимую информацию, создают условия для участия граждан в обеспечении пограничной безопасности. Граждане участвуют на добровольных началах в обеспечении пограничной безопасности в составе общественных объединений, добровольных народных дружин, в качестве внештатных сотрудников и в иных формах. Закон предусматривает формы участия как военнослужащих, так и граждан, не включенных в состав государственного органа. Тем не менее, участие в обеспечении пограничной безопасности урегулировано фрагментарно и не предусматривает гарантии правового статуса и меры стимулирования, что не исключает низкую эффективность такой деятельности.

Модельный закон «О пограничных ведомствах (силах)» [14] в ст. 17 «Правовая и 
социальная защита личного состава пограничных ведомств (сил)» определяет наряду с правовым статусом лиц, входящих в состав пограничных ведомств, особенности правового статуса граждан. Если воспрепятствование исполнению лицами, входящими в состав пограничных ведомств, обязанностей по обеспечению пограничной безопасности, посягательство на жизнь, здоровье, честь и достоинство, имущество таких лиц и членов их семей влекут уголовную или административную ответственность, то противоправные деяния в отношении граждан и членов их семей влекут ответственность, установленную законами государства. Социальная защита лиц, непосредственно участвующих в обеспечении пограничной безопасности, гарантируется законодательством государства. Данные положения аналогичны ст. 30 Модельного закона «О пограничной безопасности» за тем исключением, что нормы последнего именуют лиц, входящих в состав пограничных ведомств, военнослужащими. Следует отметить первичность установления специальных обязанностей в их правовом статусе по сравнению с правами.

В ходе работы Межпарламентской Ассамблеи СНГ в 2015-2016 гг. планируется рассмотреть рекомендации по сближению и гармонизации национального законодательства стран СНГ в сфере противодействия терроризму и экстремизму, преступностью на почве национальной, расовой и религиозной нетерпимости. Меры, направленные на предупреждение и профилактику экстремизма, должны носить приоритетный характер, что следует закрепить в национальном законодательстве в качестве одного из основных принципов противодействия преступлениям на почве национальной, расовой и религиозной нетерпимости. При этом профилактика экстремизма, прежде всего в молодежной среде, должна стать задачей широкого круга органов государственной власти, органов местного самоуправления, институтов гражданского общества и средств массовой информации. В качестве одного из основных механизмов решения приоритетных задач по профилактике экстремизма может быть предложен программно-целевой метод, предусматривающий принятие и реализацию комплексных целевых программ. В целях повышения эффективности и координации работы по профилактике экстремизма может быть предусмотрено создание на региональном и местном уровнях постоянно действующих рабочих групп (общественных советов) по противодействию экстремизму из числа сотрудников органов государственной власти, органов местного самоуправления, представителей научной и творческой интеллигенции, общественных деятелей, священнослужителей.

Важнейшим направлением системы мониторинга за проявлениями экстремизма может стать мониторинг, прежде всего, национальных доменов Интернета на предмет выявления держателей сайтов, провайдеров и отдельных лиц, размещающих и распространяющих экстремистские материалы. В связи с этим будет обсуждаться предложение по включению в национальное законодательство стран СНГ положений, устанавливающих механизмы закрытия таких сайтов, ограничения доступа пользователей к Интернет-ресурсам, содержащим экстремистские материалы, а также меры ответственности за их размещение в Интернете.

В 2017-2020 гг. планируется разработка модельных законов об участии институтов гражданского общества в обеспечении национальной безопасности и о правовом регулировании ограничения и использования деятельности частных военных компаний в обеспечении безопасности стран СНГ. Принятие данных законов необходимо в условиях изменения характера современных военных конфликтов и военных угроз. 
Анализ основных внутренних военных угроз позволяет сделать вывод о том, что особо острыми являются проблемы стабилизации внутриполитической и социальной ситуации в стране, противодействия терроризму, экстремизму и информационному воздействию на население, в первую очередь на молодых граждан страны, имеющему целью подрыв исторических, духовных и патриотических традиций. В современном мире используются разные средства ослабления стабильности конституционного строя конкретного государства. Опасность их применения усиливается в условиях планирования акций провокационного характера на период предстоящих в России избирательных кампаний 2016-2018 гг., что было отмечено В.В. Путиным [15], что также показало проведение президентских выборов в Республике Беларусь в 2015 г. Революционная волна захватила в 2010 2011 гг. такие арабские страны, как Ирак, Иран, Тунис, Алжир, Египет, Йемен, Ливия, Сирия, Бахрейн, Иордания, Оман, Марокко, выражены протесты в Судане, Джибути, Ливане, Саудовской Аравии, Кувейте, Мавритании, Западной Сахаре. Уличные погромы прошли в 2011 г. в Великобритании, Швеции и др. В 2013 г. волна революций коснулась Турцию, Таиланд. В 2014-2015 гг. наблюдались попытки революционных выступлений в КНР, в 2015 г. - ФРГ. Не исключение страны постсоветского пространства: Грузия (2003 г.), Украина (2004, 2014 гг.), Киргизия $(2005,2010$ гг.), Узбекистан (2005 г.), Белоруссия (2006 г.), Армения (2008, 2015 гг.), Молдавия (2009 г.), Россия (2008, 2011-2012 гг.). Учитывая социальную основу этих действий, использование противником социального недовольства граждан и провоцирование настроений гражданского общества против своего государства, необходимо выработать правовые механизмы повышения легитимности государственной власти и сохранения стабильности конституционного строя, когда население будет в состоянии самостоятельно противостоять деструктивному влиянию. В современных условиях глобализации, высокой мобильности населения, миграционных потоков и скорости распространения информации отказ от использования участия в обеспечении безопасности государства, в том числе мигрантов - граждан иностранного государства, может привести к возникновению серьезных военных угроз, что подтверждают события 13 ноября 2015 г. во Франции [16]. Поэтому особую актуальность приобретает участие граждан в обеспечении безопасности государства в условиях провоцирования межнациональной и социальной напряженности, экстремизма, разжигания этнической и религиозной ненависти и вражды.

История не раз показывала необходимость участия граждан в обеспечении безопасности государства для решения наиболее острых проблем в кризисные периоды его существования. При этом отсутствие общепризнанной научной концепции участия граждан в странах СНГ в обеспечении национальной безопасности актуализирует эти проблемы. Состояние мер защиты конституционного строя и обеспечения безопасности государства отражает потребность не только в реагировании на возникшие угрозы и правонарушения как свершившиеся факты, выражающиеся, в частности, в установлении уголовной ответственности за финансирование экстремистской деятельности и распространение экстремистских материалов, но и разработке мер по предупреждению подобных действий и пресечению распространения деструктивного влияния. При этом в военно-правовой науке подчеркиваются недостатки последующего, а не перспективного законодательного регулирования механизмов противодействия угрозам безопасности государства [17], в то 
время как действующее законодательство недостаточное внимание уделяет предупредительным правовым мерам предотвращения военных угроз.

Модельный закон об участии институтов гражданского общества в обеспечении национальной безопасности перспективен в плане выработки положений о формах участия граждан (индивидуальных и коллективных, прямых и косвенных и т.д.) в обеспечении безопасности государства, а также правовом статусе таких лиц. Особое внимание разработчиков должно быть обращено на деятельность граждан в составе общественных объединений политической и социальной направленности, в том числе патриотической, поддержке деятельности граждан, участвующих в текущей деятельности государственных органов, в частности, при осуществлении содействия и сотрудничества при обеспечении пограничной безопасности. Модельный закон «О пограничной безопасности» содержит только упоминание о такой деятельности, не предусматривая ее гарантии, что приводит к низкой эффективности такой деятельности.

Модельный закон о частных военных компаниях должен быть направлен на выработку положений, касающихся правового статуса частных военных компаний, деятельность которых будет связана с обеспечением государственных интересов как самого государства, на территории которого они зарегистрированы, так и интересов государства - участника СНГ, заинтересованного в участии на его территории такой компании. Полагаем недопустимым осуществление ее деятельности сугубо в коммерческих целях.

В условиях фундаментального изменения правил, средств, субъектов, объектов, целей ведения войны, применения забастовок, митингов, демонстраций и иных легальных средств выражения мнения в целях изменения существующего конституционного строя значимым является решение задачи по выработке принципиальных положений, касающихся участия граждан и организаций, в том числе специальных, в обеспечении безопасности государства, охраны его конституционной стабильности. Несмотря на то, что исторический опыт свидетельствует о существенном вкладе граждан, не наделенных специальным правовым статусом, в обороноспособность и безопасность страны, в настоящее время механизм привлечения граждан в условиях, когда мирное время превратилось в состояние угрозы агрессии, не разработан.

Актуальность правового регулирования деятельности частных военных компаний возрастает в условиях сокращения численности органов и организаций в составе военной организации государства. Кроме того, наличие таких компаний и их участие в иностранных государствах позволяет от имени государства не вмешиваться в дела суверенных государств в таких сферах, как военное строительство и военно-техническое сотрудничество.

Как известно, в Российской Федерации дважды предпринимались попытки регламентировать деятельность частных военных компаний $[18,19]$. По замыслу одного из проектов под такой компанией предполагалось понимать юридическое лицо, имеющее специальное разрешение (лицензию) Федеральной службы безопасности, специализирующееся на оказании военных и охранных услуг государству, физическим и юридическим лицам (в том числе иностранным) на договорной основе. Предполагалось, что принятие закона не повлечет расходов, покрываемых за счет федерального бюджета, и не приведет к изменению финансовых обязательств государства. Однако, поскольку законопроектом предусмотрено возложение полномочий на органы государственной власти, в том числе по осуществлению государственного надзора, 
лицензированию и введении нового сбора, их реализация приведет к расходам, покрываемым за счет средств федерального бюджета. Такие законопроекты могут быть внесены только при наличии заключения Правительства РФ. Данное заключение получено не было.

Полагаем нецелесообразным предусмотреть специальные требования о регистрации юридических лиц и ввести специальный порядок в отношении частных военных компаний, возлагая такие функции на органы безопасности, которые должны, осуществлять полномочия по лицензированию и контролю за их деятельностью. В то же время предложения [20] о наделении данных организаций статусом саморегулируемых организаций могли бы быть реализованы в условиях принятия соответствующего модельного закона [21], что может как осложнить, так и облегчить государственный контроль за их деятельностью. Реализация данного подхода, с одной стороны, сняла бы проблемы, с которыми столкнулись законодатели при принятии законопроектов о частных военных компаниях, а с другой стороны, бремя лицензирования такой деятельности легло бы на саморегулируемые организации, что также не исключает возникновение аналогичных проблем. При этом стоит отметить вопросы, связанные с использованием ими оружия, что не может быть исключено из предмета государственного контроля. Считаем возможным поддержать подход о законодательном регулировании деятельности частных военных компаний, предусматривающий допуск под строгим контролем государства частных организаций для оказания услуг военного назначения и расширение законодательно закрепленного в законе о военно-техническом сотрудничестве перечня услуг военного назначения с включением в него военно-охранных услуг [22].

В современном мире прослеживаются тенденции политизации, двойных стандар- тов, интернационализации и универсализации прав и свобод и механизмов их защиты, постепенного «вытеснения» национального государства из сферы прав человека и замены его наднациональными институтами, что является серьезной угрозой для суверенитета и целостности государства. Поэтому необходима скорейшая выработка правовых положений, направленных на усиление национального влияния на данную сферу, основанную на балансе прав и обязанностей, правовых ограничениях и ответственности личности.

Участие граждан в обеспечении безопасности государства выступает разновидностью участия в управлении делами государства при реализации не только долга и обязанности по защите Отечества, но и права, вытекающего из принципа народовластия. Правовой статус граждан включает в себя права, обязанности, гарантии, ответственность, ограничения. При этом субъективное право предполагает правомочия пользоваться благом, на собственные действия, право требования и право притязания (на защиту).

Институт участия граждан в обеспечении безопасности государства сочетает в себе процессуальные и материальные нормы различных отраслей права, которые взаимно обуславливают основания, формы, виды, процедуру участия и его правовые последствия, а также связаны с правоприменительной деятельностью государственных органов. Особенностью института является сочетание императивного и диспозитивного методов правового регулирования, в правовом регулировании преобладают межотраслевые принципы.

Данный правовой институт является комплексным в связи с тем, что предмет правового регулирования составляют формы участия граждан в соответствующей деятельности при реализации норм различных отраслей права (военного, конституционного, 
административного), находят сочетание императивный (в случае участия гражданина в обеспечении безопасности в составе военной организации государства) и диспозитивный (когда гражданин участвует без включения в состав военной организации государства) методы правового регулирования.

Участие граждан в обеспечении безопасности государства является общеправовым институтом, необходимым для любого государства. Исторический опыт показывает, что основаниями участия в обеспечении безопасности государства являются, во-первых, патриотизм, духовно-нравственная составляющая конституционная долга, во-вторых, намерение защиты от массовых нарушений прав, агрессии противника, обеспечение своих законных интересов. При этом государство всегда стремилось контролировать наиболее сильные проявления активности граждан. Участие граждан, как наделяемых правовым статусом военнослужащего, так и не наделяемым таковым, основывается на исполнении долга по защите Отечества, и защите своих прав и законных интересов, отражающих его правовую связь с государством, принадлежность к гражданам этого государства, что выступает формой легитимации конституционного строя, органов государственной власти и действующего законодательства.

Участие граждан в обеспечении безопасности в узком смысле означает участие в текущей деятельности в формах содействия, сотрудничества и взаимодействия. Оно предполагает, что граждане, принимая участие, не приобретают специальный правовой статус, связанный с формированием органа или организации в составе военной организации государства. Участие в обеспечении безопасности государства в широком смысле предполагает также исполнение воинской обязанности, прохождение военной службы по контракту, иные формы, предполагающие формирование органа или организации, а также осуществление общественного контроля в качестве последующего вида участия.

Участие граждан в обеспечении безопасности государства, являясь комплексным и общеправовым институтом, может быть непосредственным и опосредованным, прямым и косвенным, гласным и негласным. Правовая природа данного института определяется его сущностью и эволюцией и состоит в том, что с точки зрения объективного права участие граждан в обеспечении безопасности государства является формой народовластия. С точки зрения субъективного права оно вытекает, с одной стороны, из права на участие в управлении делами государства, с другой стороны, связано с исполнением долга и обязанности по защите Отечества. Содержание института составляет деятельность граждан, связанная с реализацией субъективных прав и исполнением юридических обязанностей.

Правовой статус гражданина, участвующего в обеспечении безопасности государства, связан с реализацией права и исполнением конституционных долга и обязанности, что налагает на него ответственность, влечет дополнительные права и обязанности, вытекающие из существа участия, а также наделяет правом требования предоставления условий участия. Гражданин имеет право на предоставление компенсаций и льгот в случае причинения вреда. В целях стимулирования граждан к реализации субъективного права необходимо предусмотреть стимулирующие меры.

Граждане как субъекты обеспечения безопасности государства являются участниками отношений, регулируемых нормами военного и иных отраслей права. Элементами правового статуса являются место и роль субъекта обеспечения безопасности исходя из формы и вида участия, общие и специальные права, имеющиеся в системе возни- 
кающих правоотношений, общие и специальные обязанности, возложенные на него, ограничения общих и специальных прав, юридическая ответственность за совершение правонарушений, гарантии. В соответствии с этим правовой статус может общим и специальным, а также следует выделить общую и специальную правоспособность и общую и специальную дееспособность.

Привлечение граждан к участию в обеспечении безопасности предполагает применение стимулирующих, ограничительных и защитных правовых мер и действий по привлечению граждан к участию в обеспечении безопасности государства. Такая позиция основана на том, что участие в обеспечении безопасности является и правом, формой народовластия, и обязанностью, долгом гражданина, что не требует специальных разрешительных, удостоверяющих, регистрационных действий, по общему правилу, но влечет применение ограничений.

Ограничительные меры имеют особое значение в правовом статусе такого субъекта, поскольку правовая природа рассматриваемого правового института связана с конституционной обязанностью, определенной в качестве долга. Обязанности имеют первостепенное значение даже в случаях добровольного, диспозитивного участия в обеспечении безопасности государства. Наделение лица определенными обязанностями выступает одним из правовых средств ограничений прав и свобод, что позволяет говорить об особом месте последних в правовом статусе таких граждан.

Поскольку в правовом статусе преобладают обязанности, необходимо применение стимулирующих и защитных мер при привлечении граждан к участию в обеспечении безопасности государства. Гарантиями правового статуса граждан являются гарантии реализации прав и обязанностей и гарантии охраны и защиты правового статуса, применение которых в деятельности уполномоченных органов заключается в реализации стимулирующих и защитных правовых мер обеспечения участия граждан в рассматриваемой деятельности.

Гарантии реализации прав и обязанностей граждан включают в себя льготы, компенсации, различные формы материального и нематериального стимулирования, перечень которых не является закрытым и определяется формой и видом участия граждан в обеспечении безопасности государства. При этом чем большим объемом прав наделяется гражданин, тем больше ограничений в его правовом статусе, что предполагает соответствующее качественное и количественное увеличение обязанностей и применение стимулирующих и защитных мер. В связи с высокой социальной значимостью института участия граждан в обеспечении безопасности государства, сочетанием императивного и диспозитивного методов правового регулирования соответствующих правоотношений стимулирующие меры должны предусматривать применение как материального, так и нематериального стимулирования. Гарантии охраны и защиты правового статуса граждан включают общие и специальные способы защиты, определяемые в зависимости от вида правового статуса гражданина, привлечение к юридической ответственности за нарушение требований законодательства и др.

\section{Библиография:}

1. Биюшкина Н.И., Кирюшина Н.Ю., Шартынова А.В. Добровольчество в России: проблемы правового регулирования (история и современность): моногр. - М.: Юрлитинформ, 2015. $-176 \mathrm{c}$.

2. Василенко В.И. Проблемы регулирования взаимоотношений гражданского общества с органами власти в интересах безопасности страны // Социология власти. - 2012. № 2. С. 193-201. 
3. Залужный А.Г., Тохтарбаев С.М. Взаимодействие органов внутренних дел с институтами гражданского общества в борьбе с коррупцией // Современное право. 2015. № 4 С. 120-125.

4. Красинский В.В. Участие общественного сектора в борьбе органов безопасности с терроризмом и экстремизмом // Российский журнал правовых исследований. 2015. № 1 (2). С. 171-174.

5. Майоров В.И. Деятельность полиции с ориентацией на общественность // Административное право и процесс. 2015. № 5. С. 21-24.

6. Модельный закон «О публично-частном партнерстве»: Принят на 41 пленарном заседании МПА СНГ (постановление № 41-9 от 28 ноября 2014 г.). URL: http://www.iacis.ru/upload/iblock18e/prilozhenie_k_ postanovleniyu_9.pdf (дата обращения: 25.10.2015).

7. Рекомендации по совершенствованию и гармонизации национального законодательства государств - участников СНГ в сфере обеспечения информационной безопасности: Приняты на 38 пленарном заседании МПА СНГ (постановление № 38-20 от 23 ноября 2012 г.) // Информационный бюллетень. 2012. № 56 .

8. Модельный закон «О добровольчестве (волонтерстве)»: Принят на 42 пленарном заседании МПА СНГ (постановление № 42-15 от 16 апреля 2015 г.). URL: http://www.iacis.ru/upload/iblock/9e4/prilozhenie_k_ postanovleniyu_42_15.pdf (дата обращения: 25.10.2015).

9. Модельный закон «О патриотическом воспитании»: принят на 42 пленарном заседании МПА СНГ (постановление № 42-6 от 16 апреля 2015 г.). URL: http://www.iacis.ru/upload/iblock/fc0/prilozhenie_k_ postanovleniyu_42_6.pdf (дата обращения: 25.10.2015).

10. Модельный закон «О противодействии терроризму»: Принят на 33 пленарном заседании МПА СНГ (постановление № 33-18 от 3 декабря 2009 г.) // Информационный бюллетень. 2010. № 46. С. 256.

11. Модельный закон «О противодействии экстремизму»: Принят на 32 пленарном заседании МПА СНГ (постановление № 32-9 от 14 мая 2009 г.) // Информационный бюллетень. 2009. № 44. С. 205.

12. Модельный закон «О приграничном сотрудничестве»: Принят на 29 пленарном заседании МПА СНГ (постановление № 29-18 от 31 октября 2007 г.) // Информационный бюллетень. 2007. № 41. С. 486.

13. Модельный закон «О пограничной безопасности»: Принят на 35 пленарном заседании МПА СНГ (постановление № 35-10 от 28 октября 2010 г.) // Информационный бюллетень. 2011. № 49. С. 113-144.

14. Модельный закон «О пограничных ведомствах (силах)»: Принят на 37 пленарном заседании МПА СНГ (постановление № 37-10 от 17 мая 2012 г.) // Информационный бюллетень. 2012. № 55. С. 157.

15. Выступление В. Путина на заседании коллегии ФСБ 26 марта 2015 г. URL: http://www.discred.ru/news/s rossiej_takie_shtuchki_ne_prokhodjat_vystuplenie_vladimira_putina_na_zasedanii_kollegii_fsb/2015-0326-11308 (дата обращения: 25.10.2015).

16. Директор Центра анализа мировой торговли оружием Игорь Коротченко считает, что трагедия в Париже следствие того, что Запад не пошел на совместную борьбу с ИГИЛ в Сирии. URL: http://www. kp.ru/daily/26458.5/3328336/ (дата обращения: 14.11.2015).

17. Кудашкин А.В. Проблемы законности применения Вооруженных Сил Российской Федерации в современных условиях // Военное право. 2009. № 4. URL: http://www.voennoepravo.ru/node/3735 (дата обращения: 25.10.2015).

18. Проект федерального закона № 62015-6 «О государственном регулировании создания и деятельности частных военных компаний». URL: http://asozd2.duma.gov.ru/main.nsf/\%28SpravkaNew\%29?OpenAge $n t \& R N=62015-6 \& 02$ (дата обращения: 25.10.2015).

19. Проект федерального закона № 630327-6 «О частных военно-охранных компаниях». URL: http://asozd2. duma.gov.ru/main.nsf/\%28SpravkaNew\%29?OpenAgent\&RN=630327-6\&02 (дата обращения: 25.10.2015).

20. Кудашкин А.В. К вопросу о саморегулировании в деятельности по оказанию частных услуг военного назначения: проблема выбора правовой модели // Военное право. 2015. № 2. URL: http://www. voennoepravo.ru/node/5659 (дата обращения: 25.10.2015).

21. Модельный закон «О саморегулируемых организациях»: Принят на 29 пленарном заседании МПА СНГ (постановление № 29-7 от 31 октября 2007 г.) // Информационный бюллетень. 2007. № 41. С. 144.

22. Старцун В.Н. Научная школа военного права и создание нормативной правовой основы деятельности по оказанию частных услуг военного назначения: точки сопряжения // Военное право. 2015. № 1. URL: http://www.voennoepravo.ru/node/5612 (дата обращения: 25.10.2015). 
23. Грудцына Л.Ю., Петров С.М. Власть и гражданское общество в России: взаимодействие и противостояние // Административное и муниципальное право. - 2012. - 1. - С. 19 - 29.

24. Антонов В.Ф. Правовое регулирование социально активного поведения // Политика и Общество. 2015. - 5. - C. 579 - 585. DOI: 10.7256/1812-8696.2015.5.13793.

\section{References (transliterated):}

1. Biyushkina N.I., Kiryushina N.Yu., Shartynova A.V. Dobrovol'chestvo v Rossii: problemy pravovogo regulirovaniya (istoriya i sovremennost'): monogr. - M.: Yurlitinform, 2015. - $176 \mathrm{~s}$.

2. Vasilenko V.I. Problemy regulirovaniya vzaimootnoshenii grazhdanskogo obshchestva s organami vlasti v interesakh bezopasnosti strany // Sotsiologiya vlasti. - 2012. № 2. S. 193-201.

3. Zaluzhnyi A.G., Tokhtarbaev S.M. Vzaimodeistvie organov vnutrennikh del s institutami grazhdanskogo obshchestva v bor'be s korruptsiei // Sovremennoe pravo. 2015. № 4 S. 120-125.

4. Krasinskii V.V. Uchastie obshchestvennogo sektora $v$ bor'be organov bezopasnosti s terrorizmom i ekstremizmom // Rossiiskii zhurnal pravovykh issledovanii. 2015. № 1 (2). S. 171-174.

5. Maiorov V.I. Deyatel'nost' politsii s orientatsiei na obshchestvennost'// Administrativnoe pravo i protsess. 2015. № 5. S. 21-24.

6. Kudashkin A.V. Problemy zakonnosti primeneniya Vooruzhennykh Sil Rossiiskoi Federatsii v sovremennykh usloviyakh // Voennoe pravo. 2009. № 4. URL: http://www.voennoepravo.ru/node/3735 (data obrashcheniya: 25.10.2015).

7. Kudashkin A.V. K voprosu o samoregulirovanii v deyatel'nosti po okazaniyu chastnykh uslug voennogo naznacheniya: problema vybora pravovoi modeli // Voennoe pravo. 2015. № 2. URL: http://www.voennoepravo. ru/node/5659 (data obrashcheniya: 25.10.2015).

8. Startsun V.N. Nauchnaya shkola voennogo prava i sozdanie normativnoi pravovoi osnovy deyatel'nosti po okazaniyu chastnykh uslug voennogo naznacheniya: tochki sopryazheniya // Voennoe pravo. 2015. № 1. URL: http://www.voennoepravo.ru/node/5612 (data obrashcheniya: 25.10.2015).

9. Grudtsyna L.Yu., Petrov S.M. Vlast' i grazhdanskoe obshchestvo v Rossii: vzaimodeistvie i protivostoyanie // Administrativnoe i munitsipal'noe pravo. - 2012. - 1. - C. 19 - 29.

10. Antonov V.F. Pravovoe regulirovanie sotsial'no aktivnogo povedeniya // Politika i Obshchestvo. - 2015. -5. - C. 579 - 585. DOI: 10.7256/1812-8696.2015.5.13793. 